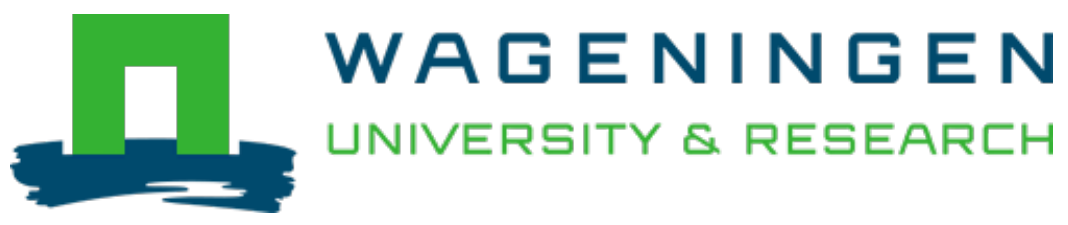

\title{
Enhancing the digestibility of cowpea (Vigna unguiculata) by traditional processing and fermentation
}

Food Science and Technology = Lebensmittel-Wissenschaft und Technologie

Madode, Y.E.; Nout, M.J.R.; Bakker, E.J.; Linnemann, A.R.; Hounhouigan, D.J. et al

https://doi.org/10.1016/j.lwt.2013.04.010

This publication is made publicly available in the institutional repository of Wageningen University and Research, under the terms of article $25 \mathrm{fa}$ of the Dutch Copyright Act, also known as the Amendment Taverne. This has been done with explicit consent by the author.

Article 25 fa states that the author of a short scientific work funded either wholly or partially by Dutch public funds is entitled to make that work publicly available for no consideration following a reasonable period of time after the work was first published, provided that clear reference is made to the source of the first publication of the work.

This publication is distributed under The Association of Universities in the Netherlands (VSNU) 'Article $25 \mathrm{fa}$ implementation' project. In this project research outputs of researchers employed by Dutch Universities that comply with the legal requirements of Article $25 \mathrm{fa}$ of the Dutch Copyright Act are distributed online and free of cost or other barriers in institutional repositories. Research outputs are distributed six months after their first online publication in the original published version and with proper attribution to the source of the original publication.

You are permitted to download and use the publication for personal purposes. All rights remain with the author(s) and / or copyright owner(s) of this work. Any use of the publication or parts of it other than authorised under article $25 \mathrm{fa}$ of the Dutch Copyright act is prohibited. Wageningen University \& Research and the author(s) of this publication shall not be held responsible or liable for any damages resulting from your (re)use of this publication.

For questions regarding the public availability of this publication please contact openscience.library@wur.nl 


\title{
Enhancing the digestibility of cowpea (Vigna unguiculata) by traditional processing and fermentation
}

\author{
Yann E. Madodé ${ }^{\mathrm{a}, \mathrm{b}, \mathrm{d}}$, Martinus J.R. Nout ${ }^{\mathrm{b}, *}$, Evert-Jan Bakker ${ }^{\mathrm{c}}$, Anita R. Linnemann ${ }^{\mathrm{d}}$, \\ Djidjoho J. Hounhouigan ${ }^{\mathrm{a}}$, Martinus A.J.S. van Boekel $^{\mathrm{d}}$
}

${ }^{a}$ Faculté des Sciences Agronomiques, Université d'Abomey-Calavi, Abomey-Calavi, 01 BP 526, Cotonou, Benin

${ }^{\mathrm{b}}$ Laboratory of Food Microbiology, Wageningen University, P.O. Box 8129, 6700 EV Wageningen, The Netherlands

${ }^{\mathrm{c}}$ Biometris, Applied Statistics, Wageningen University, P.O. Box 100, 6700 AC, Wageningen, The Netherlands

${ }^{\mathrm{d}}$ Food Quality and Design Group, Wageningen University, P.O. Box 8129, 6700 EV Wageningen, The Netherlands

\section{A R T I C L E I N F O}

\section{Article history:}

Received 1 August 2012

Received in revised form

27 March 2013

Accepted 11 April 2013

\section{Keywords:}

Carbohydrate digestibility

Flatulence

In-vitro

In-vivo

Stachyose

\begin{abstract}
A B S T R A C T
Flatulence is an important drawback for the consumption of legumes. Therefore, the ability of traditional processing (dehulling, boiling, soaking) and fermentation (bacterial, fungal or yeast) of cowpeas to reduce flatulence was investigated. Raw and processed cowpeas were assessed for their galactoseoligosaccharide content, the amount of gas produced by Clostridium perfringens using in-vitro cowpea digests as main carbohydrate substrate (in-vitro fermentability index) and the alveolar hydrogen concentration of the breath of 18 healthy adults after the consumption of a cowpea porridge breakfast (invivo fermentability index). Galactose-oligosaccharides could not be detected in cowpea hulls which yielded low in-vitro fermentability index as compared with other treatments. Traditional processing induced a limited reduction of raffinose and verbascose content contrary to fermentations. The in-vitro fermentability index appeared similarly high for all processed cowpea except after Rhizopus and Bacillus fermentation. The in-vivo fermentability index of fermented cowpeas was significantly lower than that of traditionally processed cowpeas. Consequently, soaking and fermentation in cowpea processing deserve further investigation and promotion.
\end{abstract}

(c) 2013 Elsevier Ltd. All rights reserved.

\section{Introduction}

Carbohydrates are the most abundant nutrients in cowpeas (Vigna unguiculata). Among the carbohydrates, galactoseoligosaccharides (GOS), resistant starch (RS), and non-starch polysaccharides (NSP) withstand the digestion in the human gastrointestinal tract mainly because of the lack of secretion of some enzymes such as $\alpha$-galactosidases required for their hydrolysis (Backhed, Ley, Sonnenburg, Peterson, \& Gordon, 2005; Tachibe, Ohga, Nishibata, \& Ebihara, 2011). Therefore, in the caecum, undigested carbohydrates can undergo fermentation by a diverse anaerobic microflora chiefly composed of Bacteroides, Bifidobacterium, Fusobacterium, and Clostridium spp. (Backhed et al., 2005; Simon \& Gorbach, 1986). This anaerobic fermentation results in the formation of several gases (hydrogen, carbon dioxide, methane, etc.) and short chain fatty acids (acetate, butyrate, propionate, etc.) (Cummings, 1983; Tadesse \& Eastwood, 1978). These gases

\footnotetext{
* Corresponding author. Tel.: +31317 484339; fax: +31 317484978

E-mail addresses: rob.nout@wur.nl, rob@ronfostec.nl (M.J.R. Nout).
}

represent the major fraction of the flatus generated after consumption of legumes whereas hydrogen sulphide and sulphur containing gases account for the fetid flatus (Hasler, 2006). Besides potential digestive disorders that may occur, flatulence caused by cowpea consumption is a natural and harmless process. Moreover, cowpea consumption provides substantial protein and energy to consumers. Indigestible compounds inducing flatus formation are frequently reported to protect humans from colon cancer and cardiovascular diseases (Lairon et al., 2005; McIntyre, Gibson, \& Young, 1993).

Flatulence is an important limitation to cowpea' acceptance, and thus its consumption, as reported by many consumers, especially city dwellers in West Africa (Madode et al., 2011). Enhancing the consumer acceptance and thus, consumption of cowpea dishes requires the reduction of their intestinal fermentability. Several studies demonstrated the efficacy of food processing in improving the digestibility of legumes by investigating the degradation of carbohydrates (Alani, Smith, \& Markakis, 1990; Egounlety \& Aworh, 2003; Falkoski et al., 2006; Gote, Umalkar, Khan, \& Khire, 2004; Onyenekwe, Njoku, \& Ameh, 2000). In these reports, GOS were focussed on as the main cause of flatus formation. Calloway, Hickey, 
and Murphy (1971), through breath and flatus analysis, reported that a total removal of GOS from soya beans did not eliminate all flatus formation. Their results suggested that undigested carbohydrates other than GOS also play a role in the flatus formation.

Consequently, this study was undertaken to identify food processing techniques that fit with the consumers' low-flatulence quality criterion by associating three research approaches that estimate the fermentability of most indigestible carbohydrates in cowpeas. This paper discussed the potential of food processing to reduce flatulence in cowpeas and the reliability of these approaches in predicting this flatulence reduction potential.

\section{Material and methods}

\subsection{Cowpeas}

Two batches of a pigmented landrace (Adjayivi) and one batch of an unpigmented landrace (Atchawe-tola) of cowpea were purchased from the International market of Dantokpa, Cotonou, Benin.

\subsection{Microbial strains}

Weissella beninensis LMG25373 was cultured in a sterile de Man Rogosa Sharpe broth tube (Merck, Darmstadt, Germany) at $30^{\circ} \mathrm{C}$ for $24 \mathrm{~h}$ to obtain $9.0 \log$ cfu of viable cells/mL.

Bacillus subtilis M112 was cultured in a Nutrient broth (Oxoid, Basingstoke, England) at $37{ }^{\circ} \mathrm{C}$ for $24 \mathrm{~h}$ until a viable count of 9.0 $\log \mathrm{cfu} / \mathrm{mL}$ was obtained.

Rhizopus microsporus LU573 was cultured onto Malt Extract Agar (Oxoid, Basingstoke, England) slants for 6 days at $30^{\circ} \mathrm{C}$. Prior to use, spores were scraped into $9 \mathrm{~mL}$ of sterile peptone physiological salt solution.

A spray-dried powder of Saccharomyces cerevisiae (Fermipan Red, DSM, The Netherlands) was suspended into sterile peptone physiological salt solution to obtain a viable cell count of $9.0 \log \mathrm{cfu} / \mathrm{mL}$.

\subsection{Cowpea processing}

\subsubsection{In-vitro study}

Fig. 1a depicts the processing techniques implemented on cowpeas for the in-vitro study.

Fraction 1 of the raw beans (RB) was immersed in water at $30^{\circ} \mathrm{C}$ for 15-60 min prior to a manual separation of the hulls (RH) from the cotyledons (RC). Both fractions were dried at $60^{\circ} \mathrm{C}$ for $24 \mathrm{~h}$.

Fraction 2 of RB was boiled until beans could be easily squeezed between two fingers (ratio beans/cooking solution was $1: 10, \mathrm{w} / \mathrm{v}$ ). Three media were used for boiling: 1 - water, 2 - bicarbonate solution ( $1 \mathrm{~g} / \mathrm{L} ; \mathrm{pH} 7.9)$ and kanwu solution $(1 \mathrm{~g} / \mathrm{L} ; \mathrm{pH} 9.8)$. Kanwu is a local rocksalt available in West-Africa, rich in bicarbonate, carbonate and minerals and used traditionally to reduce the cooking time of cowpeas. After boiling, the beans were drained to discard the boiling water and to collect the boiled beans (BBW, BBB and BBK, respectively).

Fraction 3 of RB was soaked overnight $(16 \mathrm{~h})$ in tap water at $4{ }^{\circ} \mathrm{C}$ to avoid acidification through uncontrolled fermentation, and subsequently dehulled by hand. The cotyledons were boiled in tap water (ratio cotyledons/water of $1: 10, \mathrm{w} / \mathrm{v}$ ) for $20 \mathrm{~min}$, and cooled down to room temperature. Boiling water was drained and boiled cotyledons (S16BC) were separately inoculated with the different microorganisms. One portion of S16BC was inoculated with $7.0 \log$ cfu of $B$. subtilis per gram of cotyledons, and incubated at $37^{\circ} \mathrm{C}$ for $24 \mathrm{~h}$ (BsFC). The second portion was mixed with cooled cooking water (ratio of $1: 1, \mathrm{w} / \mathrm{v}$ ), inoculated with $2 \times 7.0 \mathrm{log}$ cfu of $W$. beninensis per gram of cotyledons, and incubated at $30^{\circ} \mathrm{C}$ for $48 \mathrm{~h}$ (WbFC). The third portion was mixed with cooled cooking water (ratio of $1: 1, \mathrm{w} / \mathrm{v}$ ), inoculated with a natural enrichment of lactic acid bacteria $(2 \times 7.0 \log \mathrm{cfu}$ of total lactic acid bacteria per gram of cotyledons) and incubated at $30{ }^{\circ} \mathrm{C}$ for $48 \mathrm{~h}$ (NLFC). The lactic acid bacteria enrichment was obtained by a backslopping process (Nout, de Dreu, Zuurbier, \& Bonants-van Laarhoven, 1987) performed on the raw beans.

Fraction 4 of RB was soaked in tap water mixed with $10 \%$ soaking water from the backslopping process at $30^{\circ} \mathrm{C}$ for $24 \mathrm{~h}$. After soaking and draining, cowpeas were dehulled manually and cotyledons boiled (ratio cotyledon: water of $1: 10, w / v$ ) for 20 min. Boiling water was discarded and cotyledons were cooled, superficially dried, inoculated (4.0 log spores of $R$. microsporus per g of cotyledons) and incubated at $30^{\circ} \mathrm{C}$ for $48 \mathrm{~h}$. This fermentation resulted in a solid cowpea-tempe cake ( $\mathrm{RmFC}$ ).

All the samples of the in-vitro study were produced in duplicate experiments, freeze-dried and kept at $-20^{\circ} \mathrm{C}$ until use.

\subsubsection{In vivo study}

Fig. 1b depicts the processing techniques implemented on cowpeas for the in-vivo study.

Fraction 1 of pigmented cowpeas was boiled in water (BBW), or kanwu solution (BBK) as described for the in-vitro study. Fraction 2 of pigmented cowpeas was immersed in water at $30{ }^{\circ} \mathrm{C}$ for $5 \mathrm{~min}$, dried at $60{ }^{\circ} \mathrm{C}$ until a moisture content of $10 \%$ and dehulled by the Prairie Research Laboratory (PRL) dehuller (McWatters, 1990) for $4 \mathrm{~min}$. We obtained the dry dehulled raw cotyledons (DRC). DRC were soaked at room temperature $\left(28-30^{\circ} \mathrm{C}\right.$ ) for $24 \mathrm{~h}$ allowing a natural acidification from $\mathrm{pH} 7$ to $\mathrm{pH} 5$ to take place. We obtained the soaked/acidified cotyledons (SAC). One share of SAC was minced in a sterile mill, inoculated (with $6.0 \log$ cfu of $S$. cerevisiae per g) and incubated at $25^{\circ} \mathrm{C}$ for $72 \mathrm{~h}$. Two other shares of SAC were fermented with $R$. microsporus and $W$. beninensis as described for the in-vitro study.

All the processed samples prepared for the in-vivo study were dried at $60{ }^{\circ} \mathrm{C}$ for $24 \mathrm{~h}$, and milled in a Retsch type KM 1 mill through a $0.5 \mathrm{~mm}$ screen to obtain a shelf-stable powder.

\subsection{In-vitro digestion and fermentability}

The in-vitro digestion (enzymatic degradation and dialysis) was performed as described by Kiers, Nout, and Rombouts (2000). The suspension obtained after enzymatic digestion was centrifuged at $3000 \times \mathrm{g}$ and $4{ }^{\circ} \mathrm{C}$ for $15 \mathrm{~min}$. The pellet was washed twice and constituted the non-dissolved undigested moiety of the beans. The supernatant was dialysed in dialysis tubes against running water to collect the dissolved undigested moiety of the beans. The fermentability of these two moieties was assessed on the basis of the volume of gas released from their fermentation by Clostridium perfringens VWA GZ-1005 taken as a reference microorganism as defined by Nche, Nout, and Rombouts (1994). The volume of gas produced by $C$. perfringens was considered as the in-vitro fermentability index of the analysed product. In total, 10 cowpea products were digested and randomly fermented by $C$. perfringens. All samples were fermented and analysed in duplicate.

\subsection{In-vivo digestion and breath sampling}

Eighteen healthy volunteers ( 7 women and 11 men, aged 23-41 years with a body mass index ranging $18-25 \mathrm{~kg} / \mathrm{m}^{2}$ ) were enrolled. They were informed about the study procedures and signed a written informed consent. Three months before and during the study, none of these non-smokers took antibiotics nor reported any gastro-intestinal or lung diseases. The subjects of this study were Caucasian (4), Asian (5) and African (9).

According to the Medical and Ethical Assessment Committee of Wageningen University, this study did not fall within the scope of 


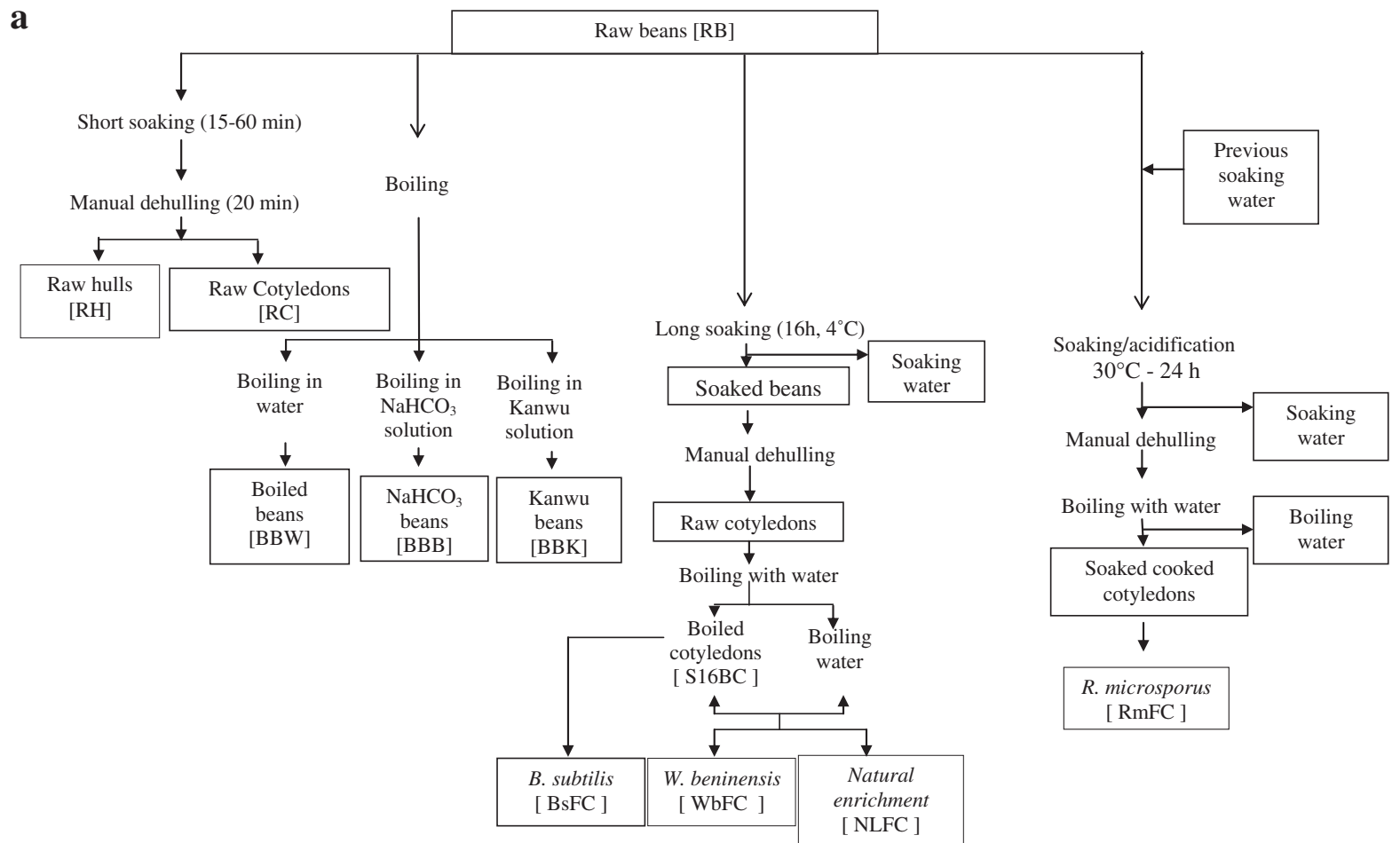

b

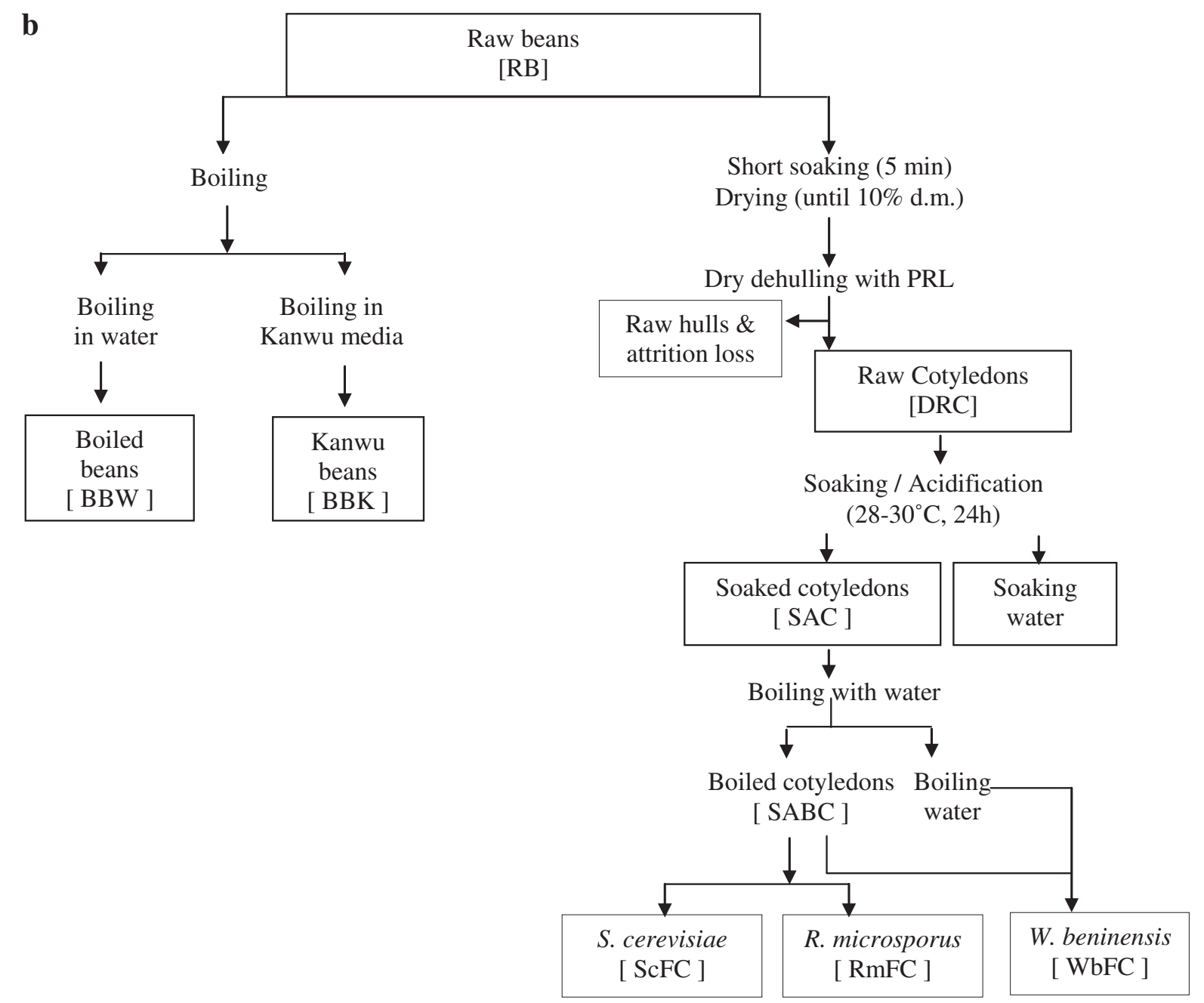

Raw beans

[RB]

Fig. 1. Flow diagram of cowpea processing for a) the in-vitro and b) in-vivo digestion studies. 
the Netherlands' law on medical scientific research on human subjects (WMO). We were advised that written informed consents from subjects would be adequate.

Raw and processed pigmented bean flours, obtained as described in section 2.3.2, were cooked with water (flour/water ratio of $1 / 10, \mathrm{w} / \mathrm{v}$ ) for $15 \mathrm{~min}$ (starting from the boiling point) to obtain porridges. After cooking, water loss due to evaporation was compensated by adding water. A preliminary test was conducted during which each participant was asked to consume the porridge until he/she had enough. Three portion sizes of porridge $(0.40,0.60$ and $0.75 \mathrm{~kg}$ ) were thus identified. Each participant would consume his portion size after a fasting period of $10 \mathrm{~h}$. The same portion size was maintained for each subject during the whole study. Alveolar breath was collected from the mouth with an alveo-sampler bag (QuinTron instrument company, Milwaukee, WI, USA) equipped with a $30 \mathrm{~mL}$ sampling syringe, on an empty stomach and hourly for $8-12 \mathrm{~h}$ after the consumption of the porridge. The subjects could take any beverage containing no indigestible sugars any time after the consumption of the porridge, but no solid food until $6 \mathrm{~h}$ after the consumption of the porridge as breakfast. The concentration of hydrogen (alveolar hydrogen) was measured in the alveolar air released by each participant using the Breath Tracker DP (QuinTron instrument company, Milwaukee, WI, USA). The alveolar hydrogen concentrations were corrected with the lowest alveolar hydrogen measured after fasting, and plotted against time (min), as shown in Fig. 2. The triangular areas under the aveolar hydrogen versus time curves were summed to obtain the area under the curve $(A U C, \mathrm{ppm} \times \min )$ :

$A U C=\Delta t \times \sum_{1}^{n}((C 1+C 2)+(C 2+C 3)+\ldots+(C n-1+C n)) / 2$

where $\Delta t=60 \mathrm{~min}$ as measurements were performed hourly; $\mathrm{C} 1$, $\mathrm{C} 2, \ldots, \mathrm{Cn}-1, \mathrm{Cn}=$ corrected $\mathrm{H}_{2}$ concentration $(\mathrm{ppm})$ at the beginning and the end of each interval; $n=$ number of $\mathrm{H}_{2}$ concentration measurements.

The experimental AUCs were normalised to normal distribution by natural logarithm (In (AUC)) and used as in-vivo fermentability index. The eighteen subjects received all treatments in a random order. Nine participants received two of the 9 treatments a second

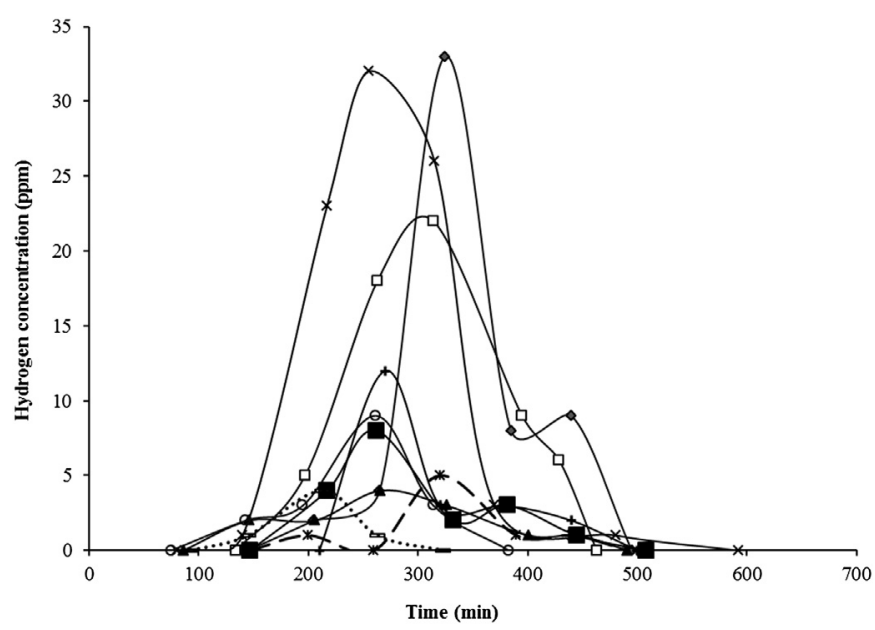

Fig. 2. Shape of $\mathrm{H}_{2}$ concentration curves from one subject during the in-vivo study RB, Raw beans; $\succ$ RC, Raw cotyledons; $\square$ BBW, Beans boiled with water; 1 BBK, Beans boiled with Kanwu solution; $-\frac{*}{-}$ SAC, Cotyledons soaked/acidified at $28-30^{\circ} \mathrm{C}$ for $24 \mathrm{~h}$; $-\mathrm{SABC}$, Boiled SAC; + RmFC, R. microsporus fermented cotyledons; - - ScFC, S. cerevisiae fermented cotyledons; - time, in order to investigate the within person-treatment variation. The subjects also filled a questionnaire to indicate the type of foods that they consumed before the fasting period and on the sampling day.

\subsection{Chemical analysis}

An aqueous extract of sucrose and GOS in raw and processed cowpea flours was prepared by suspending $0.5 \mathrm{~g}$ of flour in $50 \mathrm{~mL}$ of demineralised water and incubating the suspension at $80{ }^{\circ} \mathrm{C}$ for 20 min (Johansen, Glitso, \& Knudsen, 1996). After extraction and centrifugation at $2670 \times \mathrm{g}$ for $10 \mathrm{~min}$, the supernatant was collected, mixed (ratio 1:1) with absolute ethanol, stored at $-20^{\circ} \mathrm{C}$ for $30 \mathrm{~min}$ to precipitate dissolved proteins and centrifuged at $2670 \times \mathrm{g}$ for $20 \mathrm{~min}$. The supernatant was evaporated in a speedvac concentrator (ThermoElectron, Asheville, NC, USA) at $60^{\circ} \mathrm{C}$ for $1-2 \mathrm{~h}$. The pellet was re-suspended in water, and filtered through a $0.45 \mu \mathrm{m}$ filter. Sucrose and GOS were separated on a Prevail carbohydrate ES $5 \mathrm{u}$ column (Grace, Breda, The Netherlands) (Vinjamoori, Byrum, Hayes, \& Das, 2004) with an acetonitrile/water gradient elution (increased from 80:20 to 50:50) and detected by an Evaporative Light Scattering Detector (PL-ELS20100, Polymer Laboratories, Middelburg, The Netherlands). The standard raffinose and verbascose were produced by Fluka, Steinheim, Switzerland whereas standard sucrose and stachyose were made by Sigma, St. Louis, MO, USA. Extractions and measurements were performed in duplicate.

\subsection{Statistical analysis}

All analyses were performed in duplicate. The residual sucrose and GOS in processed cowpeas were compared using the analysis of variance followed by a Tukey posthoc test. The mean values of the in-vivo fermentability index ( $\ln ($ AUC $)$ ) were also compared through the analysis of variance followed by a Tukey posthoc test in a block design setting, with the 18 subjects as blocks. For all these tests, a significance level was 0.05 .

\section{Results}

\subsection{In-vitro assessment of the digestibility of processed cowpea}

\subsubsection{Effect of traditional processing on the digestibility of carbohydrates}

In this study, the pigmented and unpigmented cowpeas contained mainly stachyose $(42-52 \mathrm{mg} / \mathrm{g}$ d.w.) and sucrose (18$32 \mathrm{mg} / \mathrm{g} \mathrm{d.w.}$.), and less raffinose and verbascose (7-8 mg/g d.w. in both cases). Fig. 3a and b showed the sucrose and GOS profile of cowpeas as affected by dehulling, soaking at $4{ }^{\circ} \mathrm{C}$ for $16 \mathrm{~h}$ and/or boiling. The trend observed was the same for unpigmented and pigmented cowpea landraces. Raffinose and verbascose were less affected by traditional processes than sucrose and stachyose. The analysis of the hulls revealed that they did not contain significant amounts of sucrose and GOS. Taking the raw cowpeas as a reference, the use of softeners during boiling reduced the content of sucrose (60-80\%) and stachyose (48-70\%) significantly more than boiling in water (30-52\% for sucrose and $16-33 \%$ for stachyose). Soaking at $4{ }^{\circ} \mathrm{C}$ for $16 \mathrm{~h}$ followed by dehulling and boiling (S16BC) greatly reduced the sucrose and stachyose content of pigmented (69\%) and unpigmented (more than 75\%) cowpeas.

Fig. 4a showed the in-vitro fermentability index of the dissolvedand the undissolved- fractions of the undigested products as metabolized by $C$. perfringens. In all cases, the undissolved moiety contained four times more fermentable substrate than the dissolved moiety, except for the hulls where these fractions were equally fermentable for pigmented and unpigmented landraces. 
a

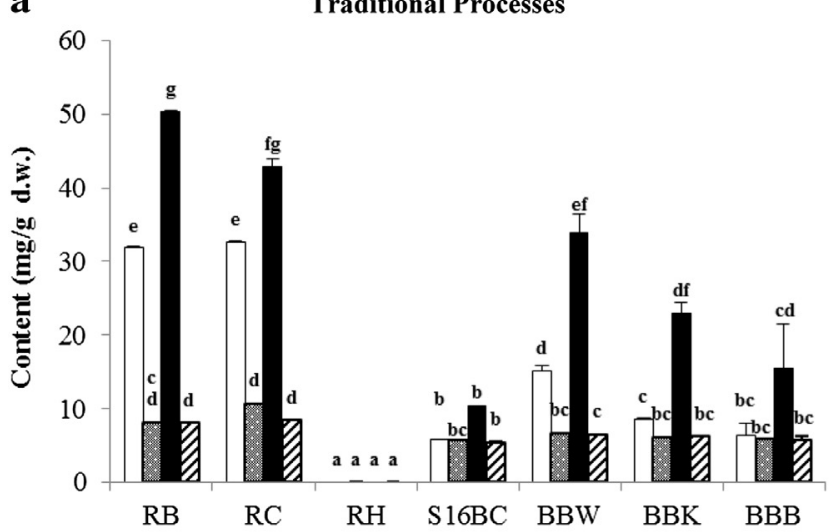

b

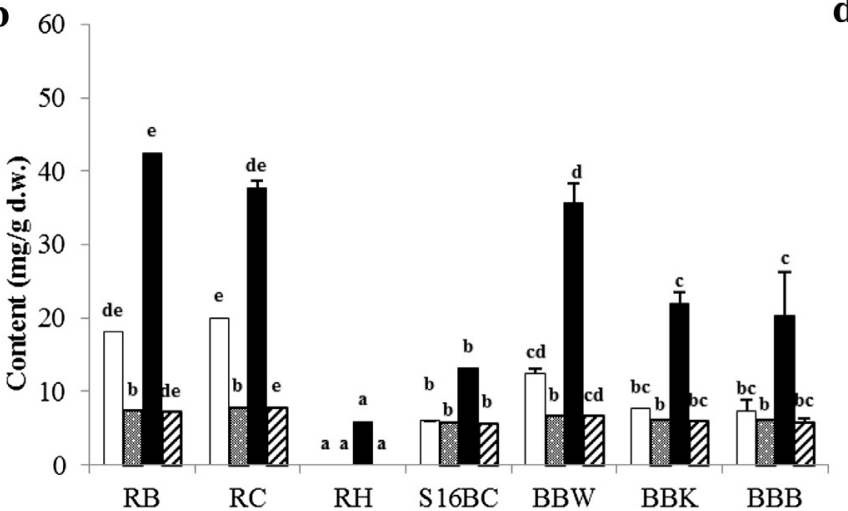

c

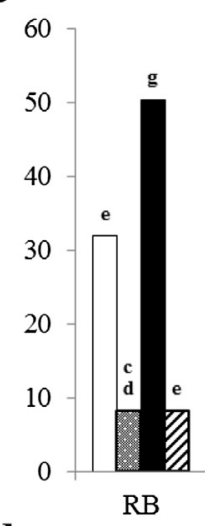

Fermentation

$\mathbf{d}_{60}$

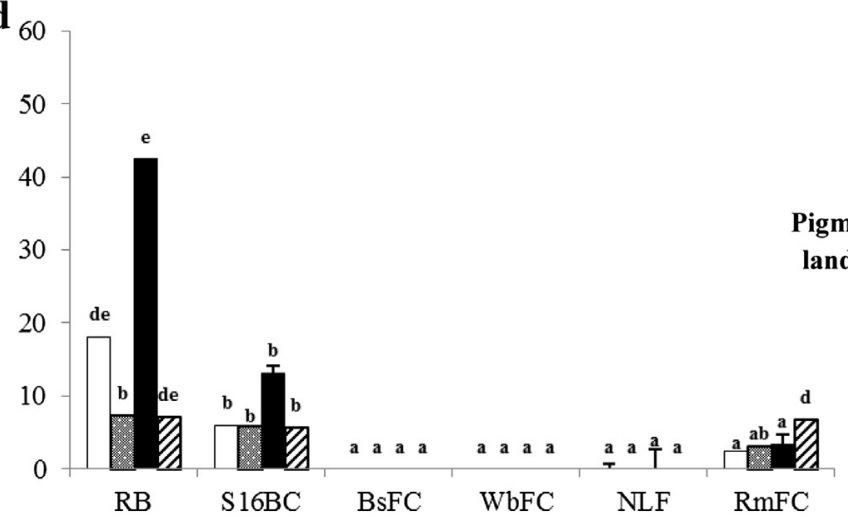

Unpigmented landrace

igmented andrace

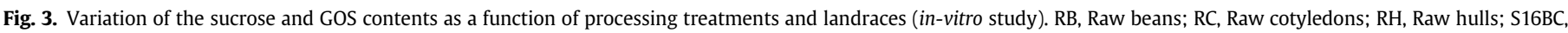

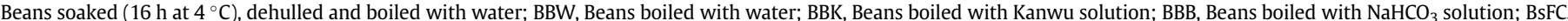

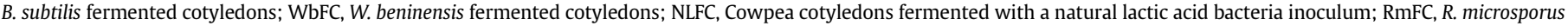

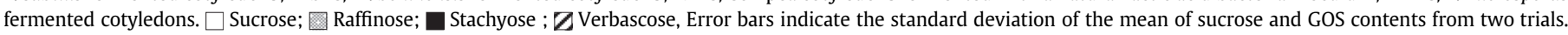

Overall, the traditional processes implemented did not significantly reduce the fermentability of cowpea assessed in-vitro.

\subsubsection{Effect of fermentation on the digestibility of carbohydrates}

S16BC was the common product leading to all biological processes except the fungal fermentation. The sucrose and GOS profiles depicted in Fig. $3 \mathrm{c}$ and $\mathrm{d}$ indicated a complete removal of sucrose and all GOS of S16BC when fermented either by B. subtilis or $W$. beninensis except verbascose. The natural lactic acid fermentation (NFLC) showed 100\% reduction of sucrose and all GOS of the pigmented landraces whereas it was less efficient to degrade stachyose and verbascose of the unpigmented landrace. The whole process of tempe production with $R$. microsporus reduced $87-100 \%$ of sucrose, $60-90 \%$ of raffinose and stachyose in raw cowpea, but hardly degraded verbascose (1-6\%).

As observed previously, the undissolved moiety of the undigested residues obtained from the bioprocessing of cowpeas was significantly more fermentable than the dissolved fraction (Fig. 4b). Lactic acid fermented cowpeas produced as much or even more gas than S16BC and raw cowpea from both landraces. B. subtilis and $R$. microsporus considerably decreased the fermentability of RB and S16BC.

\subsection{In-vivo assessment of the digestibility of cowpea}

\subsubsection{Effect of traditional processing on the digestibility of carbohydrates}

The pigmented landrace processed for the in-vivo study contained 8, 5, 40 and $10 \mathrm{mg} / \mathrm{g}$ of sucrose, raffinose, stachyose and verbascose, respectively (Fig. 5). Boiling (in water or in kanwu solution) slightly decreased the sucrose and GOS contents in the pigmented landrace, whereas dehulling slightly increased the raffinose and stachyose content on dry matter basis.

The in-vivo fermentability index of the raw cowpea porridge did not significantly differ from the index associated with the porridge made from raw cowpea cotyledons or cowpeas boiled in water. Compared with soaking of cotyledons for $24 \mathrm{~h}$ at $28-30^{\circ} \mathrm{C}$ (SAC), boiling in water did not lower the in-vivo fermentability of the cowpeas (Fig. 6a).

\subsubsection{Effect of fermentation on the digestibility of carbohydrates}

Fig. 5 shows that SAC reduced $43 \%$ of sucrose, $61 \%$ of stachyose and $15 \%$ of verbascose content of the raw cotyledons. Compared to SAC, boiling leached out all sucrose and raffinose, $32 \%$ of stachyose and $12 \%$ of verbascose. The combined effect of dehulling, soaking/ acidification and boiling was the removal of all the sucrose and the raffinose, $83 \%$ of the stachyose and $27 \%$ of the verbascose. Compared to SABC, $R$. microsporus did not reduce the sucrose and GOS contents. S. cerevisiae (ScFC) and $W$. beninensis $(\mathrm{WbFC}$ ) reduced stachyose and verbascose contents, namely by $69 \%$ and $53 \%$, respectively, for the ScFC and by $13 \%$ and $4 \%$, respectively, for the latter treatment (WbFC).

The in-vivo fermentability indexes of fermented cowpeas were all low in comparison to the other treatments (Fig. 6a). Fermentation by $W$. beninensis and $S$. cerevisiae were associated with the lowest in-vivo fermentability index compared to raw beans, and traditionally processed beans. The stachyose content of the raw and processed cowpea samples used for in-vitro and in-vivo experiments as presented in Figs. 3 and 5 were analyzed for their correlation with the in-vitro and the in-vivo fermentability index. The 

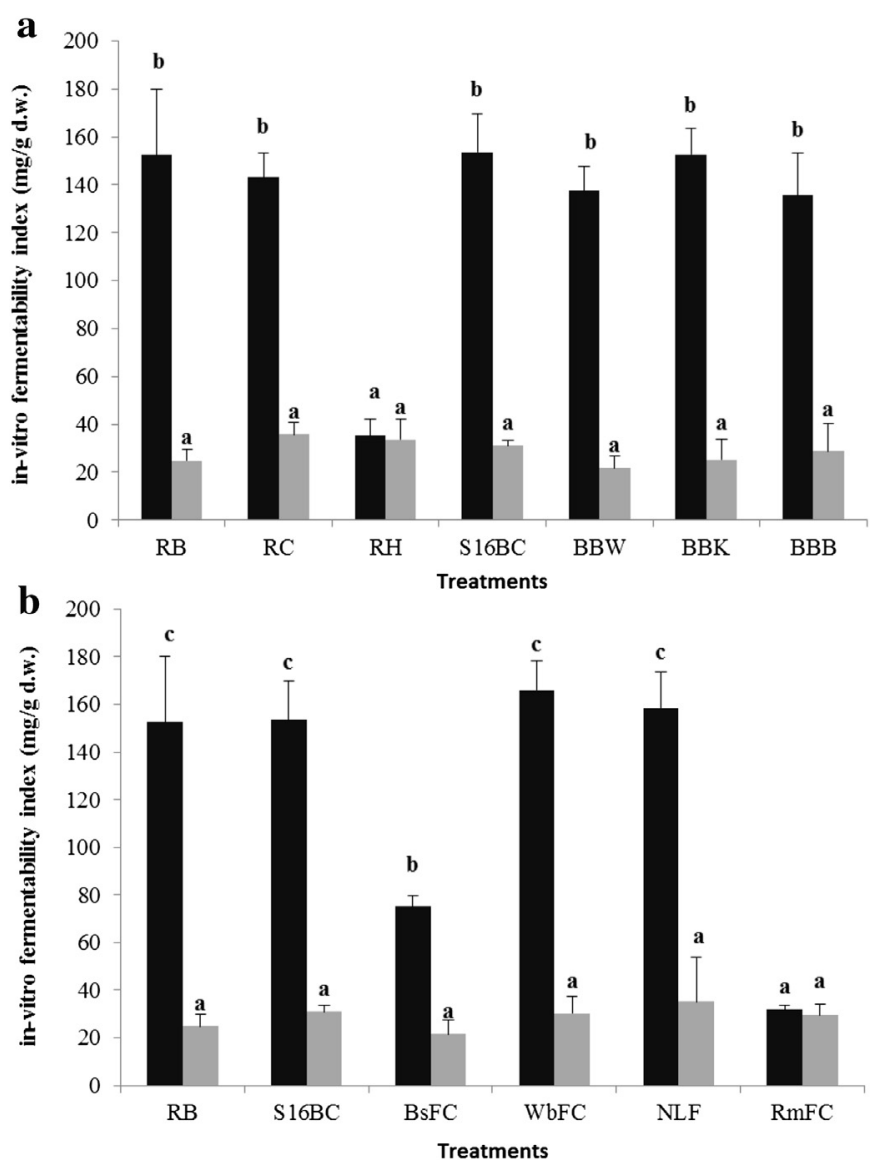

Fig. 4. In-vitro fermentability index as affected by processing treatments and landraces. RB, Raw beans; RC, Raw cotyledons; RH, Raw hulls; S16BC, Beans soaked (16 h at $4{ }^{\circ} \mathrm{C}$ ), dehulled and boiled with water; BBW, Beans boiled with water; BBK, Beans boiled with Kanwu solution; BBB, Beans boiled with $\mathrm{NaHCO}_{3}$ solution; BsFC, B. subtilis fermented cotyledons; WbFC, W. beninensis fermented cotyledons; NLFC, Cowpea cotyledons fermented with a natural lactic acid bacteria inoculum; RmFC, $R$. microsporus fermented cotyledons. $\square$ Retentate of dissolved fraction; $\square$ Undissolved fraction, Error bars indicate the standard deviation of the in-vitro fermentability index from two trials.

stachyose content of cowpeas showed a high positive correlation with the in-vivo fermentability index $(r=0.88, P=0.004)$ and no significant correlation with the in-vitro fermentability index $(r=0.370, P=0.099)$.

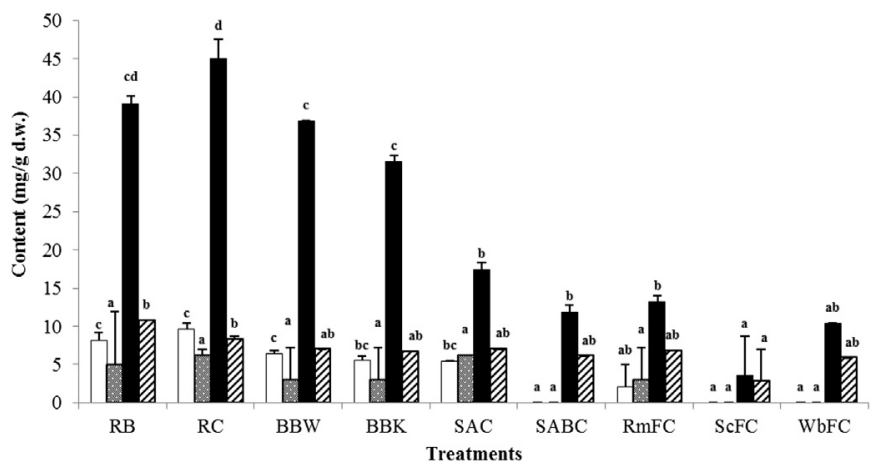

Fig. 5. Variation of the sucrose and GOS contents as a function of processing treatments (in-vivo study). RB, Raw beans; RC, Raw cotyledons; BBW, Beans boiled with water; BBK, Beans boiled with Kanwu solution; SAC, Cotyledons soaked /acidified at $28-30^{\circ} \mathrm{C}-24 \mathrm{~h}$; SABC, Boiled SAC; RmFC, R. microsporus fermented cotyledons; ScFC, $S$. cerevisiae fermented cotyledons; $\mathrm{WbFC}, W$. beninensis fermented cotyledons. Sucrose; Raffinose; $\square$ Stachyose; $\square$ Verbascose, Error bars indicate the standard deviation of the in-vivo fermentability index from two trials.
Fig. 6b illustrates that regardless of the processed cowpea consumed, the subjects involved in the in-vivo study reacted differently as they originate from Europe, Asia or Africa. Indeed, the mean in-vivo fermentability index associated with processed cowpeas increased significantly from Caucasians (7.1) to Asian (7.3) and African (7.5), meaning that Caucasians produced less abdominal gas than Asians who in turn produced less than Africans.

\section{Discussion}

Traditional processing treatments (soaking at $4{ }^{\circ} \mathrm{C}$, dehulling, and boiling) as applied separately had a lower effect on the reduction of GOS content than fermentation (lactic, yeast, fungal). Although hulls of legume seeds are commonly considered as the main causes of the high fermentability of ingested legumes, their removal by wet-manual dehulling preceded by $1 \mathrm{~h}$ soaking at room temperature reduced only $17-18 \%$ of stachyose and $30-48 \%$ of raffinose (Nwinuka, Abbey, \& Ayalogu, 1997; Onigbinde \& Akinyele, 1983). Akinyele and Akinlosotu (1991) reported, however, a higher reduction of verbascose $(76 \%)$ and raffinose (56\%) and a similar stachyose reduction (17\%) in cowpeas when beans were soaked for 10 min prior to wet-manual dehulling. The negligible amount of GOS that we detected in the hulls corroborated the findings of Revilleza, Mendoza, and Raymundo (1990) as only traces of GOS were found in the seed coat of Dolichos lablab and Mucuna pruriens. As far as cowpea is concerned, no previous study reported the content of GOS in hulls. Onigbinde and Akinyele (1983) analysed the raw cowpeas and their cotyledons and concluded, by deduction, that raffinose and stachyose abound in the testa without analysing the GOS content of the testa. The reduction observed subsequently to the dehulling process in the cotyledons as compared with the whole bean could be explained by the solubilisation of GOS in the water during the soaking process preceding the dehulling. In addition, the dehulling process is usually accompanied by the detachment of the embryo or germ which is rich in GOS. Kuo, Lowell, and Smith (1997) showed that during seed maturation, soya bean embryo as well as cotyledons are enriched in GOS contrary to hulls. Furthermore, the hulls may constitute a barrier for the diffusion of oligosaccharides into the soaking water. Therefore, the added-value of the dehulling process would be to favour the leaching of GOS or their breakdown products rather than the removal of the GOS from the hulls.

All boiling practices reduced the GOS content of the beans. The use of alkaline solutions (bicarbonate or kanwu) decreased the GOS content more than only water. The GOS might have been leached to the cooking solution. The alkaline conditions caused by the softeners probably tenderized the hulls and favoured a better release of GOS and/or their degradation products from the cotyledons into the boiling water. This leaching mechanism could also happen when cowpeas are soaked at $4{ }^{\circ} \mathrm{C}$, dehulled and cooked.

The observed reduction of stachyose content when dry cotyledons were soaked at room temperature for $24 \mathrm{~h}$ (SAC) could be due to the leaching of GOS simultaneously with their assimilation by the naturally microbiota that acidified the soaking water. $W$. beninensis was recently identified and characterised during cassava fermentation, and its ability to metabolise GOS such as raffinose and melibiose, and produce organic acids as described by Padonou et al. (2010), was confirmed by this study. The efficiency of $W$. beninensis is comparable with the enzymatic degradation by $\alpha$ galactosidase as a reduction of $93.3 \%$ of raffinose was observed by Somiari and Balogh (1992). However, the result of the fermentation by $W$. beninensis should also be considered as the sum of the effects of all the preliminary steps prior to the fermentation, namely soaking, dehulling and boiling. Although the overall effect of $R$. microsporus fermentation is high, the reduction of GOS due to the 

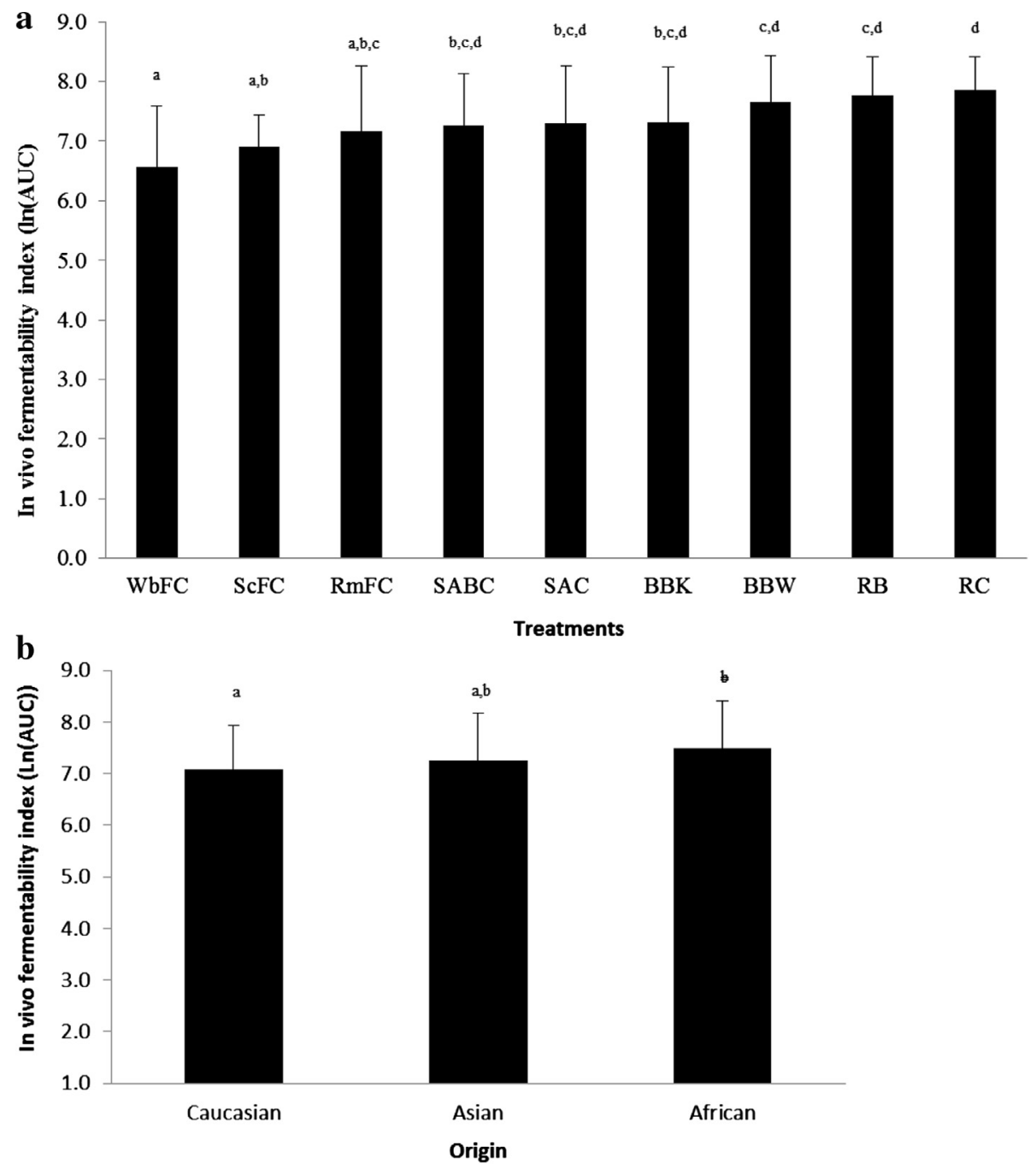

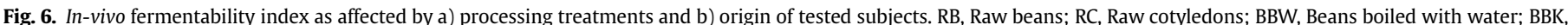

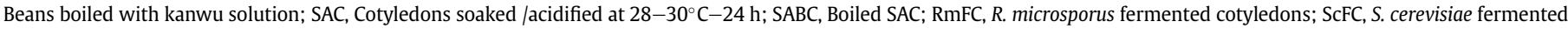

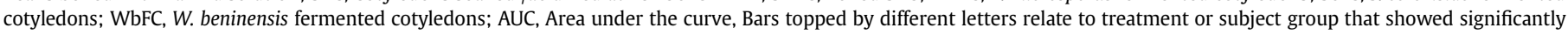
different mean values of in-vivo fermentability index $(P<0.05)$.

activity of $R$. microsporus is rather limited. Such result suggests that the fungal strain used for tempe production is unable to produce a sufficient amount of $\alpha$-galactosidase. Indeed, Rehms and Barz (1995) demonstrated that $R$. microsporus var. chinensis, contrary with Rhizopus oryzae, can produce $\beta$-fructosidase but not $\alpha$-galactosidase, enabling the entire assimilation of sucrose but only a partial degradation of raffinose.

The utilization of carbohydrates, especially GOS, varies greatly depending upon the $C$. perfringens strain used. C. perfringens type A, which is a usual human gut inhabitant, can metabolise raffinose (Nche et al., 1994; Sacks \& Olson, 1979). In our experiments, the total gas produced by $C$. perfringens in-vitro did not correlate with the amount of GOS present in the processed cowpeas. As processed cowpeas which contain a negligible amount of GOS still induce gas production, it can be suggested that $C$. perfringens can metabolize saccharides other than GOS such as resistant starch or cell wall components or their breakdown products (Calloway et al., 1971; Sacks \& Olson, 1979). This hypothesis is consistent with the fact that the undissolved fraction of the analysed samples showed more than $80 \%$ of the fermentability of the undigested residues.

The difference in intestinal response of the subjects from Europe, Asia and Africa can possibly be attributed to the differences in dietary habits. These differences could highly influence the population of the gut microflora and its activity (Backhed et al., 2005). de Fillippo et al., (2010) demonstrated that the gut microbiota of infants from rural Africa was dominated by bacteria able to utilise cellulose and xylan contrary to the gut microbiota of European children. The diet of the African children was based on foods rich in starch, fibre and plant polysaccharides whereas European children were accustomed to protein and fat rich foods. Although the non-Caucasian subjects involved in our study live in Europe for a while, most of them have not shifted drastically from their original food consumption patterns. Our study recorded that the subjects still consumed many of the foods they were used to in their country of origin.

The different approaches implemented to estimate the potential of the processed cowpea to generate flatus after consumption yielded various outcomes. The in-vivo approach (as implemented in this research) revealed the utilisation of the undigested fraction of the ingested cowpea porridges by a large range of microorganisms (Backhed et al., 2005). The in-vitro approach, as implemented in this research, involved only one bacterial strain: C. perfringens. Therefore, the type of substrate and the metabolic ability of the microbiota present with regard to this substrate can explain the observed differences. Moreover, the sampling time scale was 8- 
$12 \mathrm{~h}$ for the in-vivo test and $24 \mathrm{~h}$ for the in-vitro test. It can be hypothesized that the easily fermentable compounds in the undigested bulk, namely GOS and resistant starch, induce the formation of the hydrogen measured in-vivo during the first $12 \mathrm{~h}$ after the food is consumed (Brouns, Kettlitz, \& Arrigoni, 2002). Such hypothesis is in line with the correlation found between in-vivo fermentability index and stachyose content. The slow fermenting polymers, namely pectin, cellulose, lignin, etc. induce a significant gas release. As a matter of fact the total gas produced by C. perfringens from the various undigested materials is an integration of the gas generated by the fermentation of all the types of fermentable sugars. The $24 \mathrm{~h}$ quantification of gas production seems more appropriate to obtain a complete view of the gas production potential of processed cowpea.

\section{Conclusions}

The present research suggests that soaking and fermentation are the most efficient techniques to leach out and/or degrade flatusinducing factors present in cowpea. In the context of West Africa, soaking should be promoted as a pre-treatment in any cowpea processing procedure. Moreover lactic acid fermentation, especially with $W$. beninensis, could be optimised for low flatus induction and good taste.

The various approaches used to assess flatus production appear to express different phenomena, each of which has its own merit.

\section{Acknowledgements}

This research formed part of the TELFUN programme, Tailoring food sciences to Endogenous patterns of Local Food supply for Future Nutrition, of Wageningen University. Financial support was also obtained from the Netherlands Fellowship Programmes (Grant CF5732/2009). The authors are grateful to Zhaoying Li, Vinnie de Wilde and Judith Wolkers-Rooijackers for their skillful technical contribution and to all participants in the in-vivo study for their commitment.

\section{References}

Akinyele, I. O., \& Akinlosotu, A. (1991). Effects of soaking, dehulling and fermentation on the oligosaccharides and nutrient content of cowpeas (Vigna unguiculata). Food Chemistry, 41(1), 43-53.

Alani, S. R., Smith, D. M., \& Markakis, P. (1990). Changes in alpha-galactosidase activity and oligosaccharides during germination and incubation of cowpeas (Vigna unguiculata). Food Chemistry, 38(2), 153-158.

Backhed, F., Ley, R. E., Sonnenburg, J. L., Peterson, D. A., \& Gordon, J. I. (2005). Hostbacterial mutualism in the human intestine. Science, 307(5717), 1915-1920.

Brouns, F., Kettlitz, B., \& Arrigoni, E. (2002). Resistant starch and "the butyrate revolution". Trends in Food Science and Technology, 13(8), 251-261.

Calloway, D. H., Hickey, C. A., \& Murphy, E. L. (1971). Reduction of intestinal gasforming properties of legumes by traditional and experimental food processing methods. Journal of Food Science, 36(2), 251-255.

Cummings, J. H. (1983). Fermentation in the human large intestine: evidence and implications for health. Lancet, 1(8335), 1206-1209.

Egounlety, M., \& Aworh, O. C. (2003). Effect of soaking, dehulling, cooking and fermentation with Rhizopus oligosporus on the oligosaccharides, trypsin inhibitor, phytic acid and tannins of soybean (Glycine max Merr.), cowpea (Vigna unguiculata L. Walp) and groundbean (Macrotyloma geocarpa Harms). Journal of Food Engineering, 56(2-3), 249-254.

Falkoski, D. L., Guimarães, V. M., Callegari, C. M., Reis, A. P., De Barros, E. G., \& De Rezende, S. T. (2006). Processing of soybean products by semipurified plant and microbial $\alpha$-galactosidases. Journal of Agricultural and Food Chemistry, 54(26), 10184-10190.

de Filippo, C., Cavalieri, D., Di Paola, M., Ramazzotti, M., Poullet, J. B., Massart, S., et al. (2010). Impact of diet in shaping gut microbiota revealed by a comparative study in children from Europe and rural Africa. Proceedings of the National Academy of Sciences of the United States of America, 107(33), 14691-14696.

Gote, M., Umalkar, H., Khan, I., \& Khire, J. (2004). Thermostable $\alpha$-galactosidase from Bacillus stearothermophilus (NCIM 5146) and its application in the removal of flatulence causing factors from soymilk. Process Biochemistry, 39(11), 1723-1729.

Hasler, W. L. (2006). Gas and bloating. Journal of Gastroenterology and Hepatology, 2(9), 654-662.

Johansen, H. N., Glitso, V., \& Knudsen, K. E. B. (1996). Influence of extraction solvent and temperature on the quantitative determination of oligosaccharides from plant materials by high-performance liquid chromatography. Journal of Agricultural and Food Chemistry, 44(6), 1470-1474.

Kiers, J. L., Nout, M. J. R., \& Rombouts, F. M. (2000). In-vitro digestibility of processed and fermented soya bean, cowpea and maize. Journal of the Science of Food and Agriculture, 80(9), 1325-1331.

Kuo, T. M., Lowell, C. A., \& Smith, P. T. (1997). Changes in soluble carbohydrates and enzymic activities in maturing soybean seed tissues. Plant Science, 125(1), 1-11.

Lairon, D., Arnault, N., Bertrais, S., Planells, R., Clero, E., Hercberg, S., et al. (2005). Dietary fiber intake and risk factors for cardiovascular disease in French adults. American Journal of Clinical Nutrition, 82(6), 1185-1194.

Madode, Y. E., Houssou, P. A., Linnemann, A. R., Hounhouigan, D. J., Nout, M. J. R., \& van Boekel, M. A. J. S. (2011). Preparation, consumption, and nutritional composition of West African cowpea dishes. Ecology of Food Nutrition, 50(2), 115-136.

McIntyre, A., Gibson, P. R., \& Young, G. P. (1993). Butyrate production from dietary fiber and protection against large-bowel cancer in a rat model. Gut, 34(3), 386-391.

McWatters, K. H. (1990). Functional characteristics of cowpea flours in foods. Journal of the American Oil Chemistry Society, 67(5), 272-275.

Nche, P. F., Nout, M. J. R., \& Rombouts, F. M. (1994). Gas production by Clostridium perfringens as a measure of the fermentability of carbohydrates and processed cereal-legume foods. Food Microbiology, 11(1), 21-30.

Nout, M. J. R., de Dreu, M. A., Zuurbier, A. M., \& Bonants-van Laarhoven, T. M. G. (1987). Ecology of controlled soyabean acidification for tempe manufacture. Food Microbiology, 4(2), 165-172.

Nwinuka, N. M., Abbey, B. W., \& Ayalogu, E. O. (1997). Effect of processing on flatus producing oligosaccharides in cowpea (Vigna unguiculata) and the tropical African yam bean (Sphenostylis stenocarpa). Plant Foods for Human Nutrition, 51(3), 209-218.

Onigbinde, A. O., \& Akinyele, I. O. O. (1983). Oligosaccharide content of 20 varieties of cowpeas in Nigeria. Journal of Food Science, 48(4), 1250-1251.

Onyenekwe, P. C., Njoku, G. C., \& Ameh, D. A. (2000). Effect of cowpea (Vigna unguiculata) processing methods on flatus causing oligosaccharides. Nutrition Research, 20(3), 349-358.

Padonou, S. W., Schillinger, U., Nielsen, D. S., Franz, C., Hansen, M. Hounhouigan, J. D., et al. (2010). Weissella beninensis sp. nov., a motile lactic acid bacterium from submerged cassava fermentations, and emended description of the genus Weissella. International Journal of Systematic and Evolutionary Microbiology, 60, 2193-2198.

Rehms, H., \& Barz, W. (1995). Degradation of stachyose, raffinose, melibiose and sucrose by different tempe-producing Rhizopus fungi. Applied Microbiology and Biotechnology, 44(1-2), 47-52.

Revilleza, M. J. R., Mendoza, E. M. T., \& Raymundo, L. C. (1990). Oligosaccharides in several Philippine indigenous food legumes - determination, localization and removal. Plant Foods for Human Nutrition, 40(1), 83-93.

Sacks, L. E., \& Olson, A. C. (1979). Growth of Clostridium perfringens strains on alphagalactosides. Journal of Food Science, 44(6), 1756-1760.

Simon, G. L., \& Gorbach, S. L. (1986). The human intestinal microflora. Digestive Diseases and Sciences, 31(9), S147-S162.

Somiari, R. I., \& Balogh, E. (1992). Hydrolysis of raffinose and stachyose in cowpea (Vigna unguiculata) flour, using alpha-galactosidase from Aspergillus niger. World Journal of Microbiology and Biotechnology, 8(6), 564-566.

Tachibe, M., Ohga, H., Nishibata, T., \& Ebihara, K. (2011). Digestibility, fermentability, and energy value of highly cross-linked phosphate tapioca starch in men. Journal of Food Science, 76(6), H152-H155.

Tadesse, K., \& Eastwood, M. A. (1978). Metabolism of dietary fibre components in man assessed by breath hydrogen and methane. British Journal of Nutrition, 40(2), 393-396.

Vinjamoori, D. V., Byrum, J. R., Hayes, T., \& Das, P. K. (2004). Challenges and opportunities in the analysis of raffinose oligosaccharides, pentosans, phytate, and glucosinolates. Journal of Animal Science, 82(1), 319-328. 